\title{
Lateral Seismic Response and Self-Centering Performance of a Long-Span Railway Continuous Beam-Arch Bridge
}

\author{
Yan Shi $\mathbb{D}^{1,2}$ Zhanhong Zhang, ${ }^{1}$ Hongguo Qin, ${ }^{1}$ Xiangyu Zhao, ${ }^{1}$ and Xiong Yang ${ }^{1}$ \\ ${ }^{1}$ School of Civil Engineering, Lanzhou University of Technology, Lanzhou 730050, China \\ ${ }^{2}$ West Center of Disaster Mitigation in Civil Engineering of the Ministry of Education, Lanzhou University of Technology, \\ Lanzhou, Gansu 730050, China \\ Correspondence should be addressed to Yan Shi; syky86@163.com
}

Received 19 November 2019; Revised 7 July 2020; Accepted 13 July 2020; Published 5 August 2020

Academic Editor: Stefano Manzoni

Copyright (c) 2020 Yan Shi et al. This is an open access article distributed under the Creative Commons Attribution License, which permits unrestricted use, distribution, and reproduction in any medium, provided the original work is properly cited.

\begin{abstract}
Based on the seismic isolation design concept of functional separation, a seismic isolation system with bearings and braces combination for railway bridge was proposed. The sliding bearings afford the vertical loads, and the self-centering energy dissipation brace (SCED) and buckling restrained brace (BRB) control the horizontal displacement of the beam, so the functional separation was achieved under the combined action. Taking a long-span railway continuous beam-arch bridge as an example, the corresponding analysis model was established to study lateral seismic response and the girder's displacement pattern of the continuous beam-arch bridge under the earthquake excitations. The seismic response of bridges with different seismic isolation schemes was studied. The result showed that the presence of arch rib in a continuous beam-arch bridge amplifies the transverse displacement response of the girder compared with that in a continuous beam bridge of equal mass. The seismic isolation system with sliding bearings and energy dissipation braces can control the relative displacement between the pier and beam greatly, and the SCED can reduce or even eliminate the residual displacement between pier and beam. Furthermore, under the strong ground motions, the combined use of SCED and BRB can achieve the seismic isolation to the maximum extent when the self-centering force ratio $\zeta$, the ratio of self-centering force to superstructure weight, is 0.074 .
\end{abstract}

\section{Introduction}

The continuous beam-arch bridge is a special kind of bridge structure that consists of two structural systems, the beam bridge and arch bridge. It applies the girder's axial force organically to balance the arch's horizontal thrust. The structure's total bending moment is represented in the form of the girder in tensile and arch compression, and the shear force is the vertical component of arch pressure [1-3]. Therefore, it has the stress characteristics of both beam bridges and arch bridges.

In recent years, continuous beam-arch bridge and continuous rigid-frame bridge have attracted increasing interest in railway bridge construction because of their outstanding performance, such as large vertical stiffness, spanning capability, and excellent landscape effect [4-7]. Xie et al. [8] investigated the effect of steel section lengths on the structural mechanical behavior of rigid-frame bridges, including bending moment, bending stress, and structural deformation. Based on the results of sensitivity analysis, the bending strain energy was used as the objective function to optimize the steel section length. Pipinato and Modena [9] combined the mechanical and structural characteristics of steel-arch bridges and proposed a stepwise and practical approach for fatigue reliability assessment analysis to assess the possible remaining fatigue life of steel-arch bridges. Dai and Wang [10] studied the seismic isolation effect of speed lock-up device on continuous beam-arch bridge and found that the speed lock-up devices can reduce the pier's displacement and seismic forces significantly. Cao et al. [11] carried out a seismic design of a continuous beam-arch bridge with elastic link devices and a viscous damper and found that both devices can reduce the seismic displacement significantly. Published research revealed that large-span 
continuous beam-arch bridges' seismic behavior and stress behavior were complex and quite different from those of arch bridges and continuous beam bridges [12]. However, previous work mainly focused on continuous beam-arch bridges' seismic response and seismic isolation, while the influence of flexible arch ribs on continuous beam-arch bridge's seismic response and girder's displacement pattern was not considered. Consequently, it is necessary to analyze further arch ribs' influence on continuous beam-arch bridges' transverse seismic response to predict their seismic behavior quantitatively in different scenarios.

Seismic isolation technology is an effective means to improve structures' seismic capability and is applied widely in bridges and buildings $[13,14]$. In the past twenty years, the United States, Japan, the United Kingdom, Italy, and New Zealand have applied various types of seismic isolation devices, including laminated rubber bearings, high-damping rubber bearings, and roller bearings and the like [15-17]. Some studies have found that these isolation bearings can effectively reduce the impact of earthquake action on the superstructure and thus protect the bridge pier from earthquake damage. However, such isolation response is usually achieved at the expense of a large displacement of the bearing. The large displacement of the bearing increases the possibility of pounding and leads to the unseating of bridge decks. The earthquake-induced pounding may cause the deterioration and failure of bridge deck expansion joints $[18,19]$. In addition, there are other problems with these isolation bearings, such as unstable bidirectional deformation and residual deformation [20].

Thus, it is necessary to enhance the seismic performance of the conventional isolation bearing isolation bridge under strong earthquake. Implementing passive energy dissipation devices can be an efficient approach, since an increase in damping reduces both the force and displacement demands placed on bridges [21]. The energy dissipation devices used in bridges include buckling restrained brace, viscous damper and spring damper [22], and the emerging self-centering energy dissipation brace $[23,24]$. The recent applications of these devices in bridges have been extensively studied in numerical and experimental way. Nikkhoo et al. [25] proposed a steel pipe damper to control seismic response of the bridge; this study showed that the application of pipe damper could reduce the required flexural rigidity of the bridge. Dong et al. [26] proposed a novel type of self-centering buckling restrained brace (SC-BRB) for the seismic retrofit of double-column bridge bent. The results showed that bridges equipped with SC-BRB had smaller residual displacements. Xiang and Alam [27] used various braces to retrofit the double-column $\mathrm{RC}$ bridge bent and proposed a displacement-based design method to determine the brace parameters. The self-centering performance of the doublecolumn RC bridge bent under earthquake excitation was studied. It was shown that the PBSCs, a self-centering brace, are superior to the other braces in terms of self-centering performance by recovering more bent drift from an earthquake. The tuned mass damper was also expected to be a seismic isolation device that was installed in the bridge to control the response under earthquake excitation. The placement and tuning of the MTMDs in the bridge structures are appropriately made in order to achieve the highest response reduction possible [28-31].

In recent years, friction pendulum bearing has been widely used in bridges because of its superior seismic isolation effect and self-centering ability. Xu et al. [32] conducted seismic isolation design of a widened and reconstructed continuous steel truss by a friction pendulum seismic isolation bearing. When the designed isolation period of friction pendulum bearing is equal to $3 \mathrm{~s}$, the axial force of steel truss and internal force of pile foundation can be effectively reduced. Castaldo et al. [33] investigated the influence of soil characteristics in terms of frequency content on the seismic performance of bridges isolated with FPS isolators to estimate the optimal sliding friction coefficients. The friction pendulum bearing will have a certain vertical displacement when it moves horizontally. The railway bridges have higher requirements for track alignment and flatness, so the friction pendulum bearing may not be fully applicable to railway bridge. At present, the research on bridges' self-centering performance mainly focused on the piers [34-38], while most railway bridges adopt solid gravity piers with high rigidity and strength required to withstand elasticity in earthquakes. Therefore, railway bridges' seismic design and self-centering performance concentrate largely on the bearings.

In this paper, based on the functional separation seismic isolation design concept, a seismic isolation system comprised of bearings and braces for railway bridges was proposed. The sliding bearings afford vertical loads, and buckling restrained braces (BRB) and self-centering energy dissipation braces (SCEDs) control the horizontal displacement. This paper adopted long-span railway continuous beam-arch bridge as the research object, and its seismic response was calculated by nonlinear time-history analysis. The influence of arch rib on the continuous beam-arch bridge's lateral seismic response and displacement pattern was taken into account. In addition, the SCED and BRB braces' effects on bridge seismic isolation were studied.

\section{3D Modeling of Bridges}

2.1. Bridge Description. A typical three-span continuous beam-arch bridge was selected in this study as the proto bridge. Figure 1(a) shows the elevation view of the bridge. This bridge is a hybrid bridge and can be regarded as a combination of a three-span prestressed concrete beam and a single-span concrete-filled steel tube arch. The span of this bridge is $62 \mathrm{~m}, 132 \mathrm{~m}$, and $62 \mathrm{~m}$, respectively. The box girder's top flange is $10.6 \mathrm{~m}$ wide; its bottom flange is $6.5 \mathrm{~m}$ at the middle span and $8.9 \mathrm{~m}$ at the bearings, and its depth is $3.5 \mathrm{~m}$ at the middle span and $7 \mathrm{~m}$ at the bearings, as shown in Figures 1(b) and 1(c). This bridge has two U-type abutments and two piers whose cross section is shown in Figure 1(e). The height of the two piers is $9 \mathrm{~m}$. The cross-sectional shape of the concrete-filled steel tube arch ribs is a dumbbell, as shown in Figure 1(d). The arch ribs' height is $22 \mathrm{~m}$ and the corresponding rise-span ratio is $1 / 6$. The suspenders' spacing is $8 \mathrm{~m}$ in the bridge's longitudinal direction. The longitudinal reinforcing bars in the bridge piers have a nominal diameter 


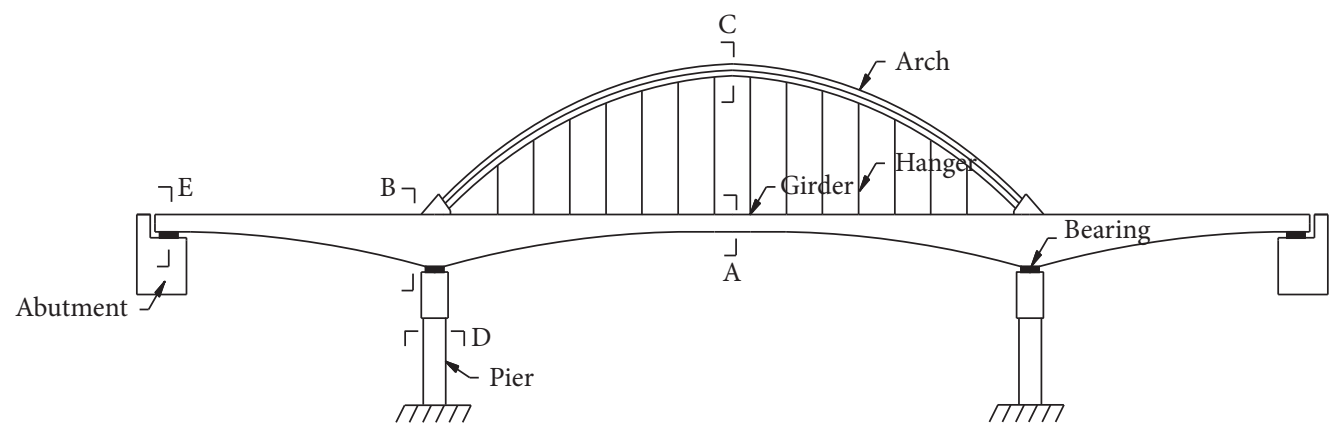

(a)

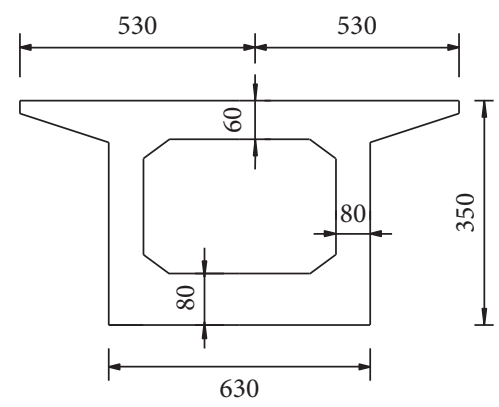

(b)

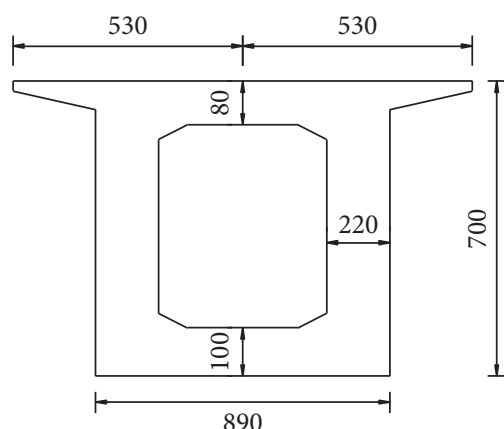

890

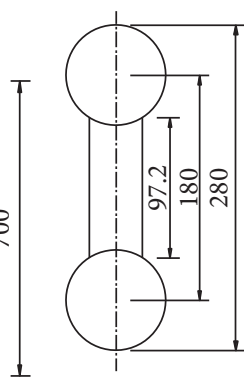

(d)

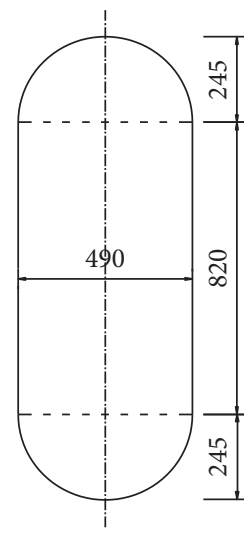

(e)

Figure 1: Long-span railway continuous beam-arch bridge (unit: $\mathrm{cm}$ ): (a) elevation view of the bridge; (b) section A-A; (c) section B-B; (d) section C-C; (e) section D-D.

of $28 \mathrm{~mm}(\Phi 28)$, and the stirrups have a nominal diameter of $12 \mathrm{~mm}(\Phi 12)$. The nominal tensile strength of the reinforcing bars is $335 \mathrm{MPa}$.

2.2. Bridge Component Modeling. Three-dimensional finite element model of the continuous beam-arch bridge was developed in OpenSees (Figure 2). The bridge structure's damping ratio was set to $3 \%$ [39], and Rayleigh damping was adopted. The influence of the bridge structure-pile-soil was not considered. The simulation method is described in detail as follows:

(1) Superstructure Modeling. The elastic beam-column element was selected to simulate the girder. The concrete-filled steel tube arch ribs were assumed to be linear-elastic and modeled by the elastic beamcolumn element. The truss element was used to simulate the suspenders.

(2) Bearing Modeling. Sliding bearings have been adopted widely in bridges to satisfy the girders' large displacement requirements. Flat Slider Bearing element was selected to simulate the sliding bearing, coulomb friction was adopted in the friction model, and the coulomb friction coefficient was set to 0.02 [40, 41]. The selected parameters are shown in Table 1.

(3) Bridge Column Modeling. Nonlinear beam elements with fiber sections were used to capture the nonlinear behavior of bridge columns. Concrete-01, a uniaxial Kent-Scott-Park concrete material in OpenSees, was used to model the concrete. Steel-02, a uniaxial material in OpenSees, was used for the simulation of the reinforcing steel.

(4) Shear Key Modeling. Sacrificial shear keys were used between the girder and the abutments to restrain the girders' lateral displacement and reduce the damage to the substructure. Shear keys at the abutments can be simulated by using the simplified elastic-plastic model. Figure 3 shows the mechanism model developed by Megally et al. [42] and Silva et al. [43] on the basis of the diagonal tension failure mechanism. The simplified model includes three stages: yield, hardening, and failure. The shear force at Levels I and II can be computed by the following equation:

$$
\begin{aligned}
& V_{\mathrm{I}}=V_{\mathrm{s}}+\left(\frac{\Delta_{\mathrm{I}}}{\Delta_{\mathrm{II}}}\right) V_{\mathrm{c}}, \\
& V_{\mathrm{II}}=V_{\mathrm{s}}+V_{\mathrm{c}},
\end{aligned}
$$

where $\Delta_{\mathrm{I}}$ is the displacement at yielding of the shear key reinforcement; $\Delta_{\mathrm{II}}$ is the displacement at peak force, and, in the simplified model, $\Delta_{\text {III }}$ is the displacement where the shear key reinforcement fails.

$V_{\mathrm{c}}$ and $V_{\mathrm{s}}$ are the concrete and reinforcement contributions to the strength of the shear key, respectively. The concrete contribution, $V_{c}$, is expressed as 


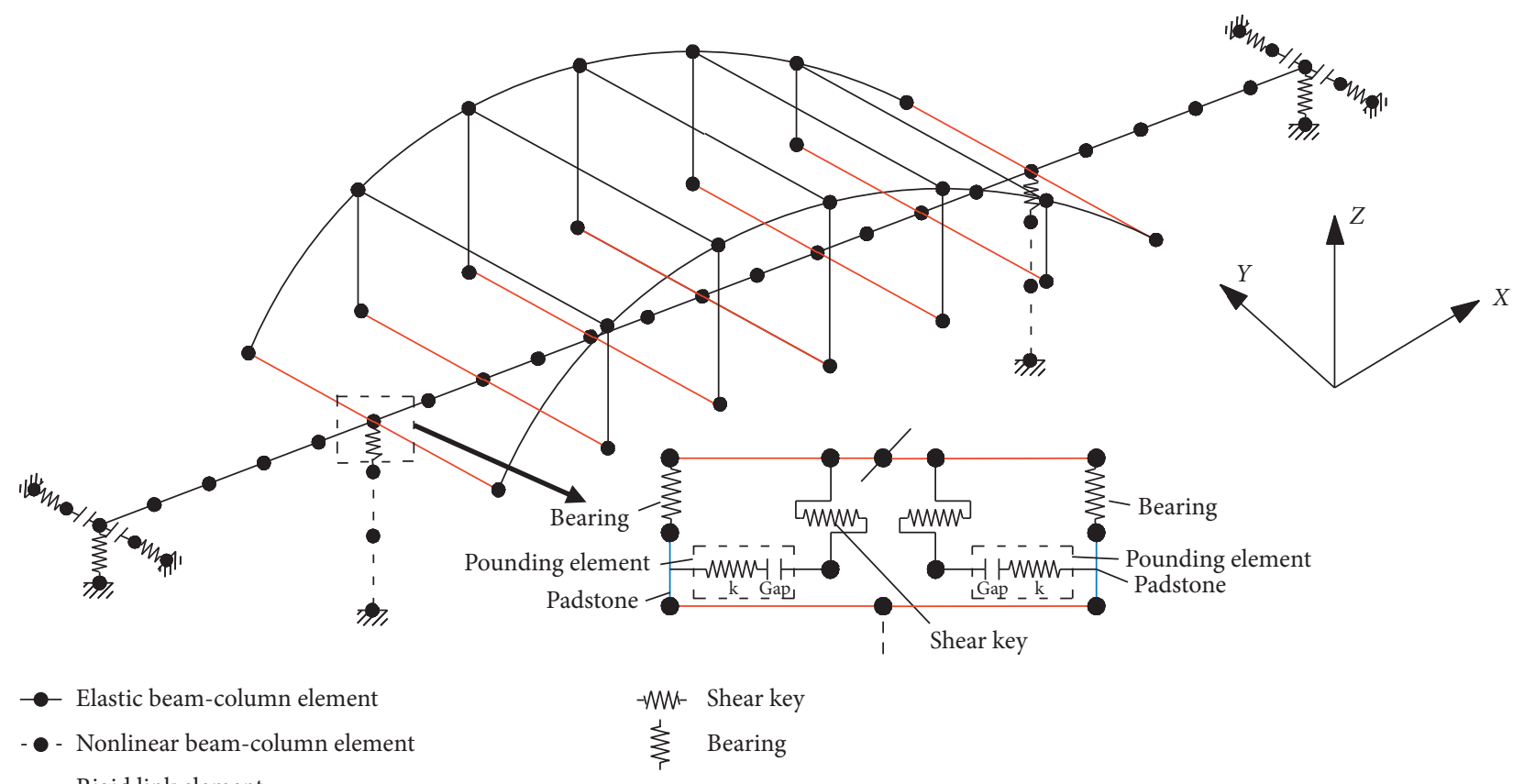

FIGURE 2: Finite element model of the prototype bridge.

TABLE 1: Parameter values for various analytical models for continuous beam-arch bridge.

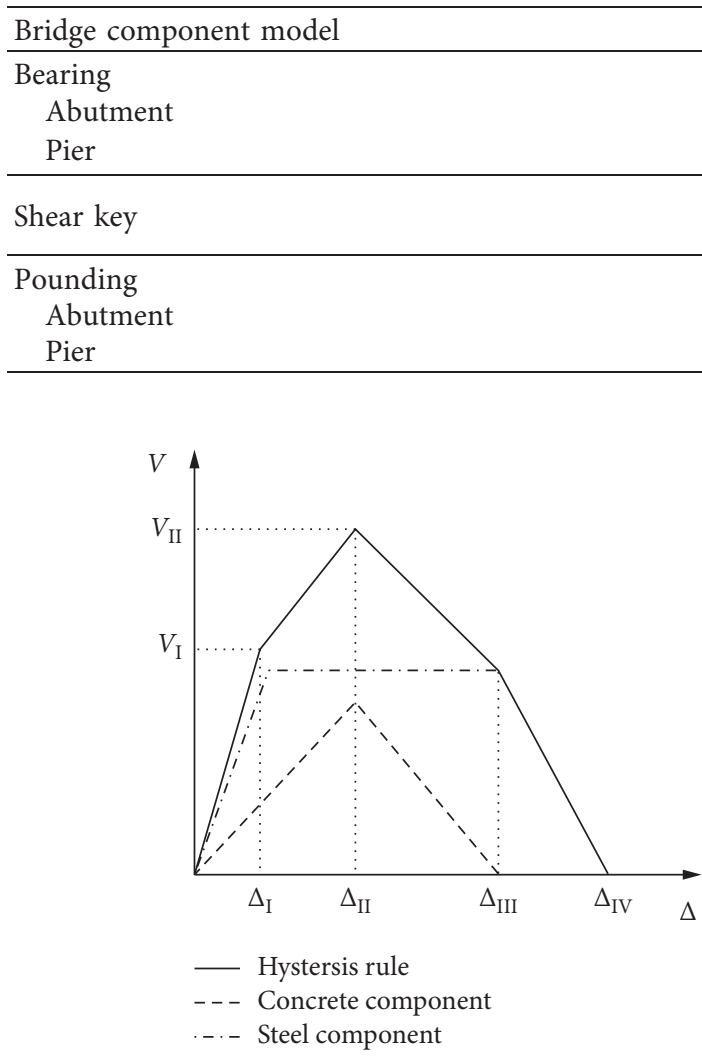

Figure 3: Analytical models of shear key.

\section{Parameters}

$F=99 \mathrm{kN}, K=33159 \mathrm{kN} / \mathrm{m}, D_{y}=0.003 \mathrm{~m}$ $F=848 \mathrm{kN}, K=282657 \mathrm{kN} / \mathrm{m}, D_{y}=0.003 \mathrm{~m}$ $V_{\mathrm{I}}=639.8 \mathrm{kN}, V_{\mathrm{II}}=886 \mathrm{kN}$ $\Delta_{\mathrm{I}}=0.0036 \mathrm{~m}, \Delta_{\mathrm{II}}=0.0115 \mathrm{~m}, \Delta_{\mathrm{IV}}=0.0573 \mathrm{~m}$

$\Delta_{\mathrm{G}}=0.03 \mathrm{~m}, K_{1}=28224 \mathrm{kN} / \mathrm{m}, K_{2}=11904 \mathrm{kN} / \mathrm{m}$ $\Delta_{\mathrm{G}}=0.03 \mathrm{~m}, K_{1}=179954 \mathrm{kN} / \mathrm{m}, K_{2}=75662 \mathrm{kN} / \mathrm{m}$

where $h$ is the height of the abutment stem wall to center of the tension tie reinforcement, $b$ is the width of the abutment stem wall, and $f_{\mathrm{c}}^{\prime}$ is the concrete compressive strength.

The steel contribution to the capacity of the shear key, $V_{\mathrm{s}}$, can be obtained by the following equation:

$$
\begin{aligned}
V_{s}= & {\left[A_{s, 1} f_{y, 1} h+A_{s, 2} f_{y, 2}(d \sin \theta+h \cos \theta)\right.} \\
& \left.+\frac{A_{s, s} f_{y, s}}{2 s}\left(n_{h} h^{2}+n_{v} d^{2}\right)\right]\left(\frac{1}{h+a}\right)
\end{aligned}
$$


where $A_{s, 1}$ and $f_{y, 1}$ are the total area of steel and the yield strength of the horizontal tension tie, respectively. $A_{s, 2}$ and $f_{y, 2}$ are the total area of steel and the yield strength of vertical shear reinforcement, respectively. $A_{s, s}$ and $f_{y, s}$ are the cross-sectional area and the yield strength of the side reinforcement, respectively. $\theta$ is the angle of the diagonal shear key wall. $n_{h}$ and $n_{v}$ are the numbers of side faces with horizontal and vertical side reinforcement (i.e., $n_{h}=n_{v}=2$ for these units).

The yield displacement, peak displacement, and limit displacement of the shear key can be calculated by

$$
\begin{aligned}
\Delta_{\mathrm{I}} & =\sqrt{2} \varepsilon_{y}\left(L_{\mathrm{d}}+L_{\mathrm{a}}\right) \frac{(h+d)}{\sqrt{h^{2}+d^{2}}}, \\
\Delta_{\mathrm{II}} & =\sqrt{2} \varepsilon_{y}\left(L_{\mathrm{d}}+L_{\mathrm{a}}\right) \frac{(h+d)}{s}, \\
\Delta_{\mathrm{IV}} & =\sqrt{2} \varepsilon_{0.01}\left(L_{\mathrm{d}}+L_{\mathrm{a}}\right) \frac{(h+d)}{s},
\end{aligned}
$$

where $L_{\mathrm{a}}$ is the cracked region, $L_{\mathrm{d}}$ is the reinforcement development length, $d$ is the depth of the shear key, $s$ is the reinforcement spacing within the stem wall, and $\varepsilon_{y}$ is the yield strain of the steel.

The values of relevant parameters in shear key are presented as follows:

$$
\begin{aligned}
f_{\mathrm{c}}^{\prime} & =20 \mathrm{MPa}, \\
b & =h=600 \mathrm{~mm} .
\end{aligned}
$$

The concrete contribution, $V_{c}$, can be calculated as

$$
V_{\mathrm{C}}=0.2 \times \sqrt{20} \times 500 \times 800=358 \mathrm{kN} .
$$

The relevant mechanical parameters of reinforcement in the shear key are shown as follows:

$$
\begin{aligned}
A_{s, 1} & =628 \mathrm{~mm}^{2}, \\
f_{y, 1} & =335 \mathrm{MPa}, \\
A_{s, 2} & =1099 \mathrm{~mm}^{2}, \\
f_{y, 2} & =335 \mathrm{MPa}, \\
A_{s, s} & =78 \mathrm{~mm}^{2}, \\
f_{y, s} & =335 \mathrm{MPa} .
\end{aligned}
$$

The reinforcement contribution, $V_{\mathrm{S}}$, can be obtained as

$$
V_{\mathrm{S}}=\frac{\left[785 \times 335 \times 500+1256 \times 335 \times 500+((78.5 \times 335) /(2 \times 200))\left(2 \times 500^{2}+2 \times 400^{2}\right)\right]}{500+250}=528 \mathrm{kN}
$$

The yield displacement, peak displacement, and limit displacement of the shear key can be calculated as

$$
\begin{aligned}
\Delta_{\mathrm{I}} & =0.002 \sqrt{2}(300+600) \frac{(400+500)}{\sqrt{400^{2}+500^{2}}}=3.6 \mathrm{~mm}, \\
\Delta_{\mathrm{II}} & =0.002 \sqrt{2}(300+600) \frac{(400+500)}{200}=11.5 \mathrm{~mm}, \\
\Delta_{\mathrm{IV}} & =0.01 \sqrt{2}(300+600) \frac{(400+500)}{200}=57.3 \mathrm{~mm} .
\end{aligned}
$$

The shear force at Levels I and II can be calculated as

$$
\begin{aligned}
& V_{\mathrm{I}}=528+\left(\frac{3.58}{11.46}\right) \times 358=639.8 \mathrm{kN}, \\
& V_{\mathrm{II}}=528+358=886 \mathrm{kN} .
\end{aligned}
$$

Steel shear keys at the piers are I-shaped with a yield strength of $235 \mathrm{MPa}$. The nonlinear beam-column element with a fiber section was used to simulate the I-shaped steel.
(5) Pounding modeling. The impact between the superstructure and the abutment in the transverse direction was modeled by using the Hertz-damp model, which can simulate the energy dissipation in pounding well. The mechanical properties of the model are shown in Figure 4. The energy loss in the pounding can be calculated by

$$
E=K_{h} \times \delta_{m}^{n+1} \times \frac{1-e^{2}}{n+1},
$$

where $K_{h}$ is the impact stiffness, the value of which is the shear key's bending stiffness; $n$ is the Hertz stiffness coefficient; $e$ is the coefficient of restitution, and $\delta_{m}$ is the maximum penetration in the impact. The effective stiffness is calculated using the following equation:

$$
K_{\text {eff }}=K_{h} \times \sqrt{\delta_{m}}
$$

The yield displacement can be computed by the following equation:

$$
\delta_{y}=a \times \delta_{m}
$$




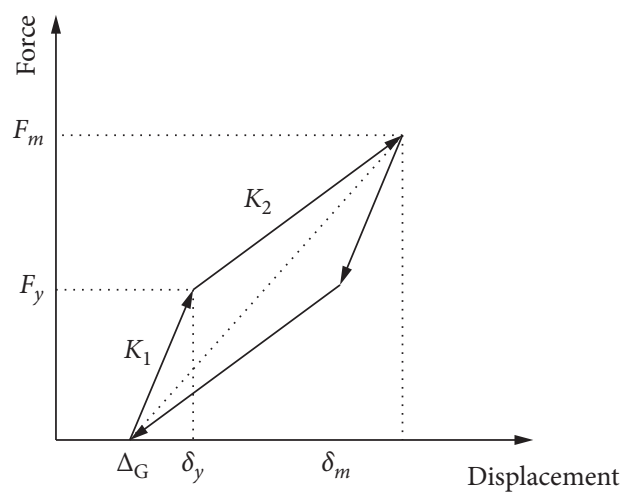

FIGURE 4: Hertz-damp model for pounding simulation.

where $a$ is the yield coefficient. The initial stiffness and the postyield stiffness in the pounding are calculated using the following equations:

$$
\begin{aligned}
& K_{1}=K_{\text {eff }}+\frac{E}{a \times \delta_{m}^{2}}, \\
& K_{2}=K_{\text {eff }}-\frac{E}{(1-a) \times \delta_{m}^{2}} .
\end{aligned}
$$

The parameters of the obtained pounding elements are shown in Table 1.

\section{Modal Analysis and Ground Motion Selection}

3.1. Natural Vibration Characteristics of the Bridge. To ensure the accuracy of the model, the dynamic analysis models of the continuous beam-arch bridge were established in both OpenSees and MIDAS/Civil. The dynamic characteristic analysis was carried out. The first three periods obtained from OpenSees and MIDAS/Civil are listed in Table 2. Figure 5 shows the vibration mode shapes of the bridge. It can be observed that the first-order and second-order mode shapes of the bridge are the transverse vibration of the arch ribs, and the corresponding periods are $2.30 \mathrm{~s}$ and $1.32 \mathrm{~s}$, respectively. The third mode shape is the transverse vibration of the girder, which indicates that the arch ribs' transverse stiffness is small. So it is necessary to investigate their influence on the lateral seismic response.

3.2. Selection of Ground Motions. To study the arch ribs' effect on the lateral seismic response of continuous beamarch bridge and the lateral displacement patterns of the girder, seven ground motions of hard site were selected from the strong ground motion record database [44] (Table 3). The average spectrum of the selected ground motions and the design spectrum are shown in Figure 6. The average spectrum of the selected ground motions is slightly smaller than the design spectrum in the short period and larger than the design spectra in the middle and long periods. So the selected ground motions satisfy the requirements of the standard design of railway bridges. The ground motions selected were applied in the transverse direction of bridge,
TABle 2: Dynamic characteristics of the continuous beam-arch bridge.

\begin{tabular}{lccc}
\hline \multirow{2}{*}{ Number } & \multicolumn{2}{c}{ Period (s) } & Description \\
& OpenSees & $\begin{array}{c}\text { MIDAS/ } \\
\text { Civil }\end{array}$ & \\
\hline 1 & 2.32 & 2.30 & $\begin{array}{c}\text { Lateral flexure of arch rib } \\
\text { Antisymmetric flexure of arch } \\
\text { rib }\end{array}$ \\
3 & 1.33 & 1.32 & \begin{tabular}{c} 
Lateral flexure of girder \\
\hline
\end{tabular} \\
\hline
\end{tabular}

and all seven sets of ground motion records were scaled to a peak ground acceleration (PGA) of $0.4 \mathrm{~g}$.

\section{Arch Rib's Influence on Lateral Seismic Response}

To investigate the arch ribs' influence on the lateral seismic response of the continuous beam-arch bridge and the girder's lateral displacement patterns, it was assumed that the girder at the abutment and pier can move freely without the constraints of the shear keys in lateral direction. Based on OpenSees seismic analysis platform, the different dynamic analysis models were established and nonlinear time-history analysis was performed. There are three different analysis models: In Model 1, a continuous beam-arch bridge model with sliding bearings was adopted. In Model 2, a continuous beam-arch bridge model with sliding bearings was adopted, the arch ribs' mass was assigned to the girder, and only the contribution of stiffness was considered in the arch ribs. In Model 3, a continuous beam bridge model with sliding bearings was adopted and the arch ribs' mass was assigned to the girder.

The first five periods of the three models are shown in Table 4. For Model 1, the transverse vibration of arch ribs was observed in the first and second mode shapes. The third mode shape was characterized by the transverse vibration of girder, and its corresponding period was $1.05 \mathrm{~s}$. The first mode shape in Models 2 and 3 was the transverse vibration of the girder, and its corresponding periods were $1.17 \mathrm{~s}$ and $1.19 \mathrm{~s}$, respectively. It can be seen that the vibration periods of the girder of Models 1, 2, and 3 are not equal because of the coupling between the components of the bridge.

Figure 7 shows the lateral displacement peak at the key positions of the girder. It can be observed that the girder's lateral displacement of Model 1 is much larger than that of Model 2 and Model 3. This phenomenon indicates that the existence of the span arch ribs magnifies significantly the displacement response of the girder. Figure 8 shows the displacement time-history curve of the girder and arch ribs of Model 1 under the Imperial Valley earthquake motion. Figure 8(a) shows that the girder and arch ribs move inphase, and this movement increases the girder's displacement response. In all three models, the transverse deformation of the girder was small, and its deformation displacement was less than $1 \mathrm{~cm}$. The girder's movement is a rigid body movement along the transverse direction of the bridge, and the higher-order vibration modes have less influence on it, which is shown in Figure 8. It can be seen in 


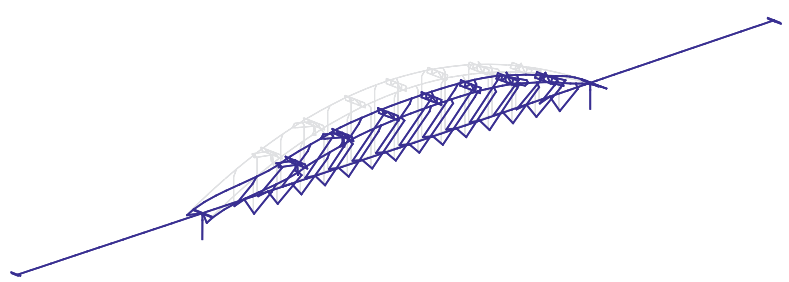

(a)

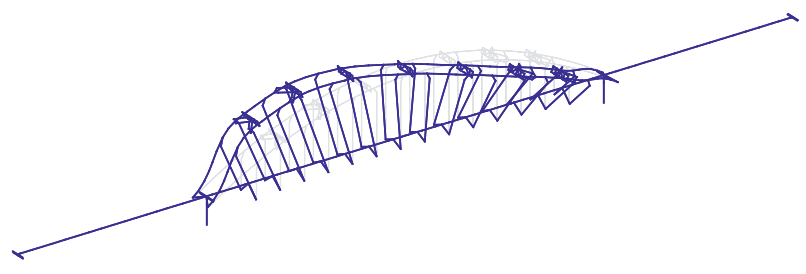

(b)

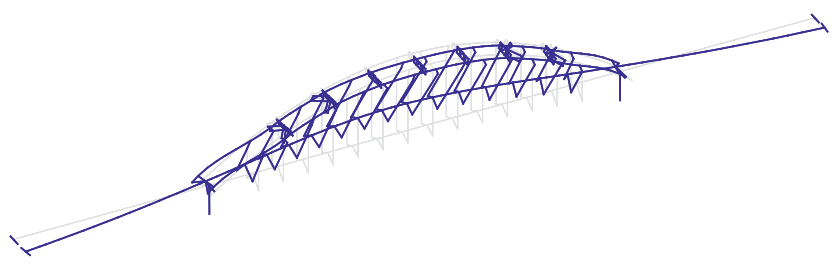

(c)

Figure 5: Three typical modal shapes (MIDAS/Civil): (a) first vibration mode; (b) second vibration mode; (c) third vibration mode.

TABLE 3: Selected ground motion recorders.

\begin{tabular}{|c|c|c|c|c|c|c|c|}
\hline Number & Earthquake & Station & Component & Year & PGA (g) & $\mathrm{PGV}(\mathrm{m} / \mathrm{s})$ & $\mathrm{PGV} / \mathrm{PGA}$ \\
\hline 1 & Imperial Valley & 6621 Chihuahua & CHI012 & 1979 & 0.27 & 0.25 & 0.92 \\
\hline 2 & Landers & 22074 Yermo Fire Station & YER270 & 1992 & 0.24 & 0.52 & 2.10 \\
\hline 3 & Northridge & 90063 Glendale-Las Palmas & GLP177 & 1994 & 0.36 & 0.12 & 0.34 \\
\hline 4 & Northridge & 90016 LA-N Faring Rd & FAR000 & 1994 & 0.27 & 0.16 & 0.58 \\
\hline 5 & Northridge & 90091 LA-Saturn St & STN020 & 1994 & 0.47 & 0.35 & 0.73 \\
\hline 6 & Imperial Valley & 6621 Chihuahua & CHI282 & 1979 & 0.25 & 0.30 & 1.18 \\
\hline 7 & Chi-Chi & CHY036 & CHY036-W & 1999 & 0.29 & 0.39 & 1.32 \\
\hline
\end{tabular}

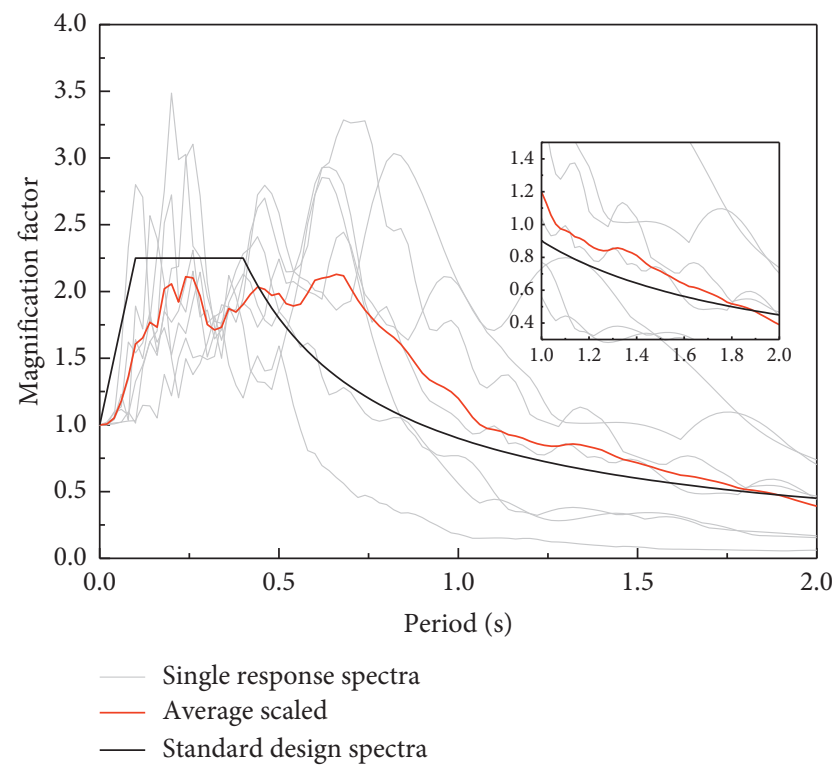

Figure 6: Spectra of selected ground motion.

Figure $8(\mathrm{~b})$ that when the girder's displacement is large, it moves primarily in-phase in the transverse direction of the bridge. When the displacement is very small, the girder may exhibit inverse movement along the transverse direction of the bridge. Since both the displacement and the structural response are very small, they can be ignored. The stiffness of
TABle 4: Period of three finite element models (units: s).

\begin{tabular}{lccc}
\hline Number & Model 1 & Model 2 & Model 3 \\
\hline 1 & 2.32 & 1.17 & 1.19 \\
2 & 1.33 & 0.73 & 0.73 \\
3 & 1.05 & 0.72 & 0.72 \\
4 & 0.73 & 0.51 & 0.52 \\
5 & 0.72 & 0.32 & 0.32 \\
\hline
\end{tabular}

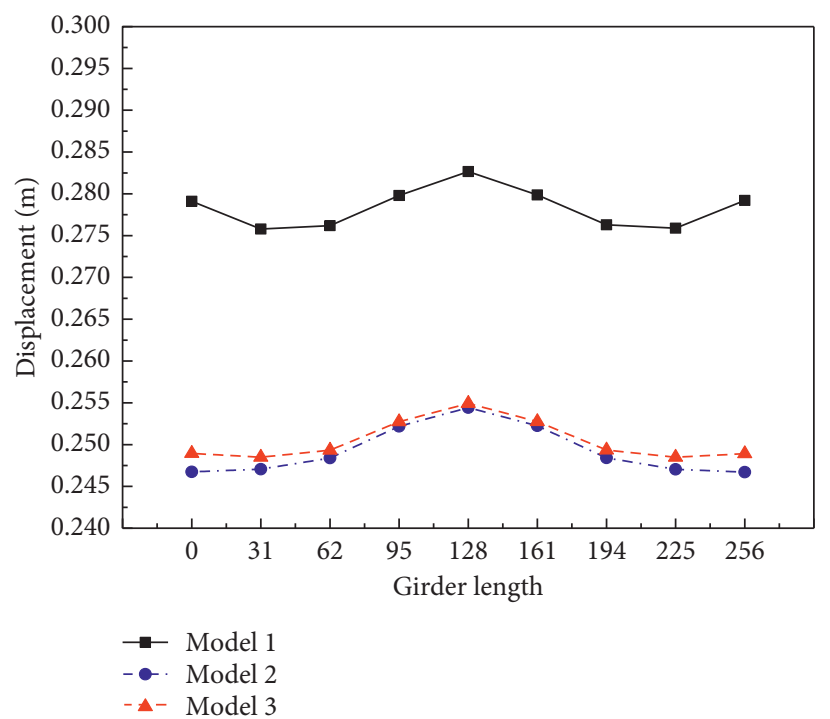

FIGURE 7: The peak displacement of key position of the girder. 


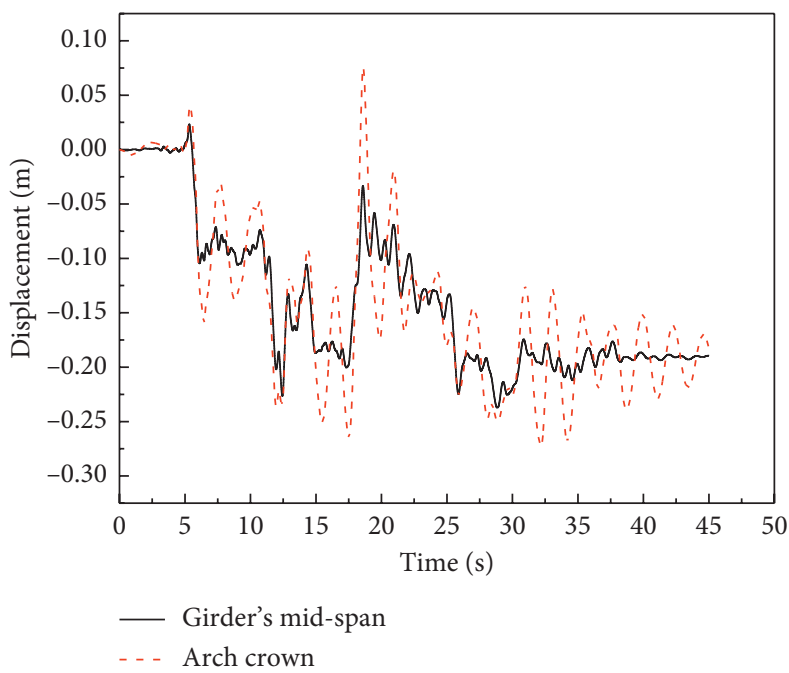

(a)

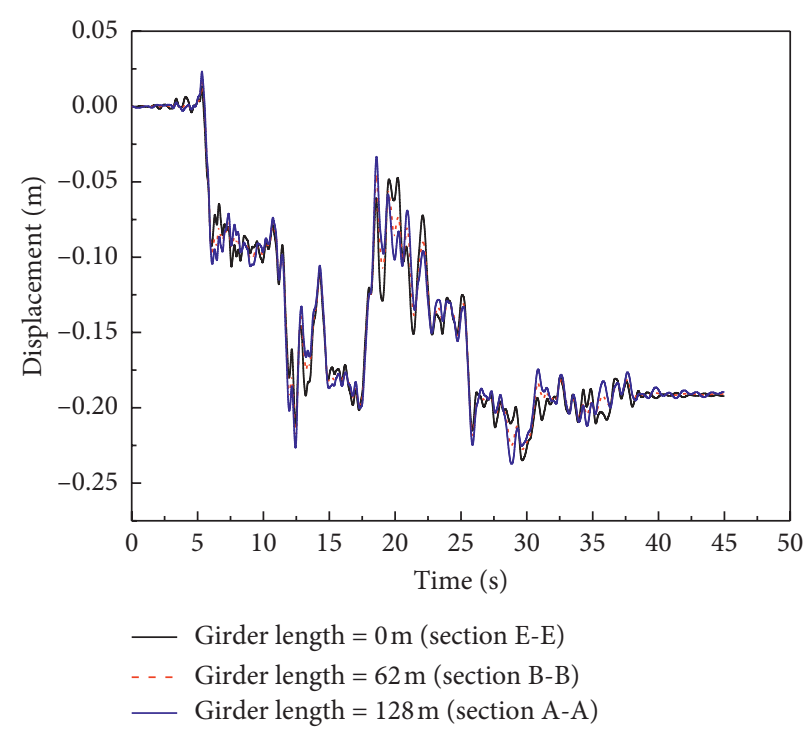

(b)

FIGURE 8: Displacement time-history curve of continuous beam-arch bridge (Imperial Valley): (a) displacement time-history curve of the girder and arch rib; (b) displacement time-history curve of the girder.

the arch ribs in Model 2 can improve the lateral stiffness of the bridge and reduce the girder's transverse displacement response, while the effect is limited. In addition, the arch ribs' stiffness increases the calculation time and the amount of work in the time-history analysis.

The above study did not consider the constraint of lateral shear keys. However, several shear keys were installed at the abutments and piers to restrain the girder's lateral displacement in fact. To consider the shear keys' restraint effect on the girder, three different finite models that considered the lateral shear keys were established. To study the seismic response of the bridge with shear keys, nonlinear timehistory analysis was carried out. Figure 9 shows the peak transverse displacement of key positions of the girder.

As Figures 7 and 9 show, the girder's transverse displacement was reduced significantly when the constraint of shear keys was taken into account. At the bearing, the displacement of the continuous beam-arch bridge's girder with shear keys' constraint decreased $61 \%$ more than the bridge without shear keys' constraint. In an analogous finding, when the lateral constraint of the shear keys was considered, the arch ribs' effect on the girder's displacement decreased compared to the bridge without shear keys' constraint. Figure 10 shows the displacement time-history response of the girder and arch ribs of Model 1. It can be observed from Figures 9 and 10 that the girder and arch ribs move in the same direction, and the arch ribs move before the girder and increase its displacement response.

In this paper, the lateral displacement patterns of girder and ribs were judged according to the coefficient of displacement variation proposed by Dwairi and Kowalsky [45]. When the coefficient of displacement variation was less than $10 \%$, the displacement pattern of the girder exhibited rigid body translation or rotation. When the coefficient of displacement variation was greater than $10 \%$, the girder

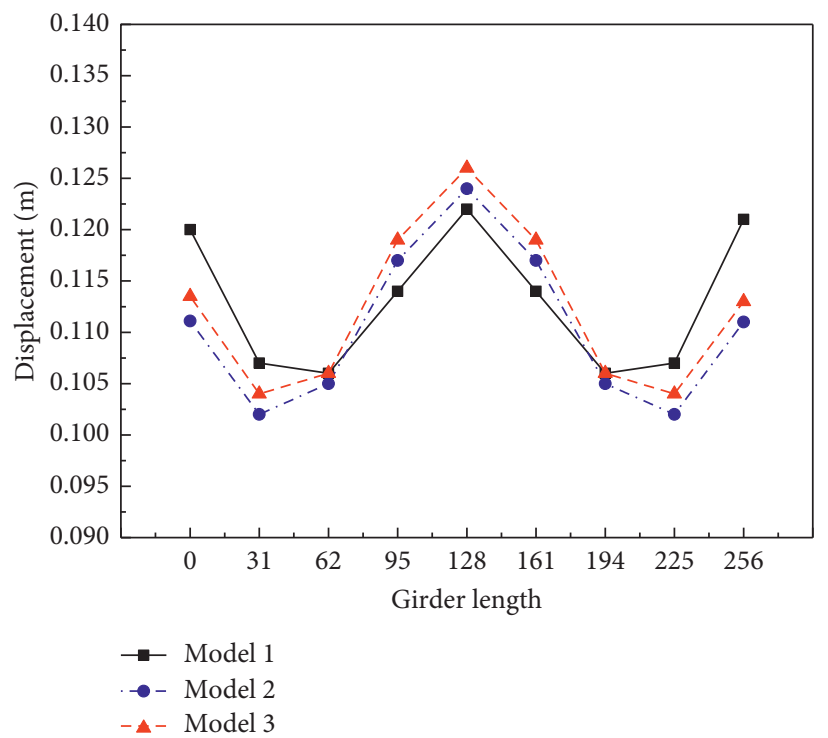

Figure 9: The peak displacement of key positions of the girder.

underwent large bending deformation. Table 5 shows the girder and arch ribs' coefficient of displacement variation and also showed that the girder's coefficient of transverse displacement was less than $10 \%$. It can be observed that the movement of the girder along the transverse direction of the bridge exhibited a rigid body translation or rotation. For arch ribs, when the constraint of shear keys was not considered, their coefficient of displacement variation was less than $10 \%$. The arch ribs' movement in the transverse direction of the bridge exhibited a rigid body translation or rotation. When the constraint of the lateral shear keys was considered, the coefficient of displacement variation of the arch ribs was approximately $33 \%$. It can be observed that the 


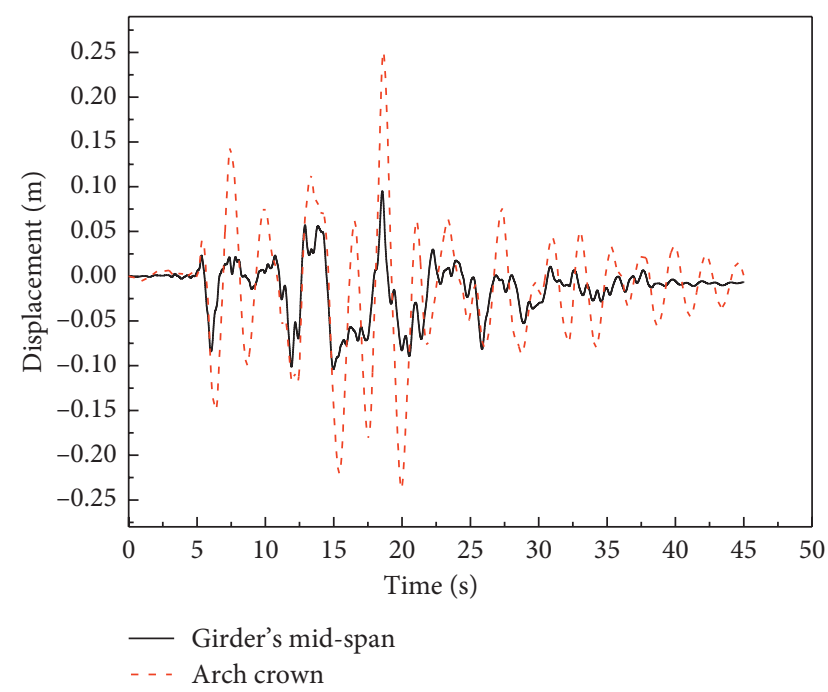

Figure 10: Displacement time-history curve of the girder and arch rib.

TABle 5: Coefficient of displacement variation of the girder and arch ribs (unit: \%).

\begin{tabular}{lcccccc}
\hline & \multicolumn{3}{c}{ Unconstraint } & \multicolumn{3}{c}{$\begin{array}{c}\text { The constraint by } \\
\text { shear keys }\end{array}$} \\
Position & \multicolumn{3}{c}{$\begin{array}{c}\text { Model } \\
\text { Model } \\
\end{array}$} & $\begin{array}{c}\text { Model } \\
2\end{array}$ & $\begin{array}{c}\text { Model } \\
\text { Model }\end{array}$ & $\begin{array}{c}\text { Model } \\
2\end{array}$ \\
\hline $\begin{array}{l}\text { Girder } \\
\text { Arch } \\
\text { ribs }\end{array}$ & $1.1(2.7)$ & $1.6(3.1)$ & $\begin{array}{c}1.2 \\
(3.4)\end{array}$ & $4.9(4.8)$ & $6.5(8.5)$ & $\begin{array}{c}6.5 \\
(7.6)\end{array}$ \\
\hline
\end{tabular}

arch ribs' transverse stiffness was small and they exhibited great flexural deformation.

The seismic response of nonlinear elements of a continuous beam-arch bridge under the Landers earthquake motion is shown in Figure 11. The hysteretic force-displacement response of the nonlinear elements indicated that (1) the concrete shear keys at the abutment reached their ultimate capacity, failed, and dissipated a certain amount of seismic energy; (2) the bearings deviated from the original position in lateral directions; (3) there was a dissipation of energy in the pounding. These phenomena suggest that all components were in the plastic stage and played important roles in resisting earthquake force and dissipating seismic energy.

\section{Seismic Response of the Seismic Isolation System}

5.1. Seismic Isolation System. A seismic isolation system that can be used in railway bridges was proposed based on the functional separation seismic isolation design concept. The system consists of bearings and braces. Two types of braces, self-centering energy dissipation braces (SCED) and buckling restrained braces (BRB), were adopted. The sliding bearings accommodate the vertical loads caused by girder, and the braces (SCED and $\mathrm{BRB}$ ) control the horizontal displacement, so the function separation is achieved under the combined action. In addition, the SCED can control the residual displacement between the pier and girder to realize the bridge's functional recoverability after an earthquake.

The hysteretic response of the SCED brace is common for self-centering systems and is characterized by a "flagshaped" hysteresis. The brace's restoring force curve is shown in Figure 12(a). In the constitutive relation, $\alpha$ represents the ratio of post-yield stiffness to initial stiffness; $\beta$ represents the ratio of loading and unloading forces, which reflects the brace's energy dissipation capacity. When $\beta$ is in the range of $0 \sim 1$, the residual displacement of the brace is zero, and the greater the value of $\beta$ is, the stronger the energy dissipation ability is; when the value of $\beta$ is greater than 1 , the brace begins to generate residual displacement. In order to achieve self-centering performance, $\beta$ in this paper is taken as $0.98[24,46]$. The BRB brace's hysteretic response is a bilinear hysteretic model, as shown in Figure 12(b). The BRB used in this article is selected from the products developed by Shanghai Research Institute of Materials [47]. According to the principle of equal strength, the mechanical properties of SCED can be determined. The mechanical parameters of braces are shown in Table 6. Two-node link element was selected to simulate the SCED and BRB, and the corresponding materials were self-centering and Steel-01, respectively. The study of SCED described in this article is based on the self-centering energy dissipation brace proposed by Dong et al. [48]. No matter what type of SCED is adopted, the constitutive relationships are not changed.

In the bridge's seismic isolation design, a seismic isolation device is installed to increase the period of the bridge and dissipate seismic energy, expecting to reduce the seismic response of the bridge structure. This requires the seismic isolation devices to be sufficiently resilient to avoid the large relative displacements and residual displacements between the pier and girder. Therefore, the design scheme of seismic isolation device is determined by nonlinear time-history analysis and test methods. According to the requirement of resilience of seismic isolation devices in the AASHTO Bridge Isolation Design Guidelines, when the lateral displacement of seismic isolation device increases from half of the target displacement to the target displacement, the increase in resilience should be no less than 0.025 times the superstructure's weight. Finally, through trial calculations, the continuous beam-arch bridge was equipped with twelve braces for seismic isolation and damage control. Two braces were mounted on each abutment and four braces were mounted on each pier to meet the seismic isolation design requirements.

5.2. Seismic Response of SCED or BRB Isolated Bridges. To study the effect of different braces on seismic isolation of continuous beam-arch bridge, the following three analysis cases were proposed: In Case 1, the bridge was not equipped with any type of braces, and constraint of shear keys was considered. BRB and SCED played the role of isolation devices in Case 2 and Case 3, respectively. In these three cases, the selected types of bearings are all the sliding 


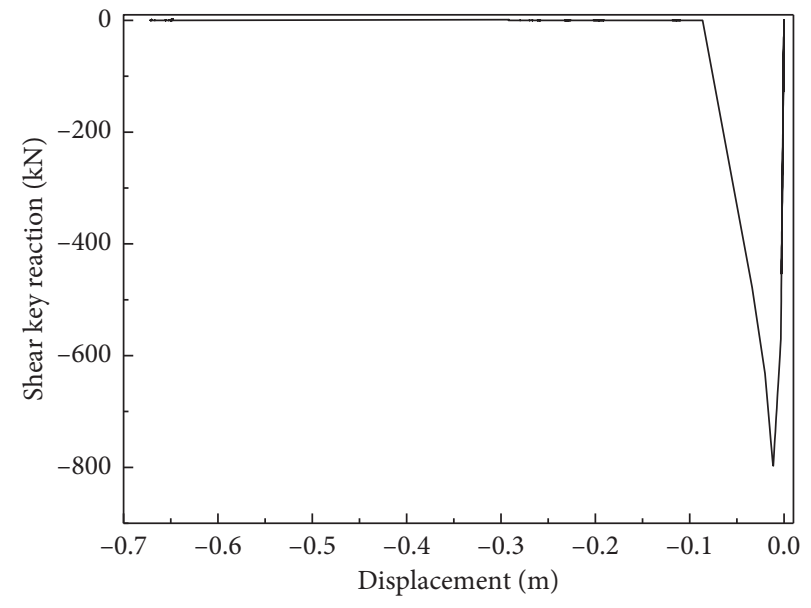

(a)

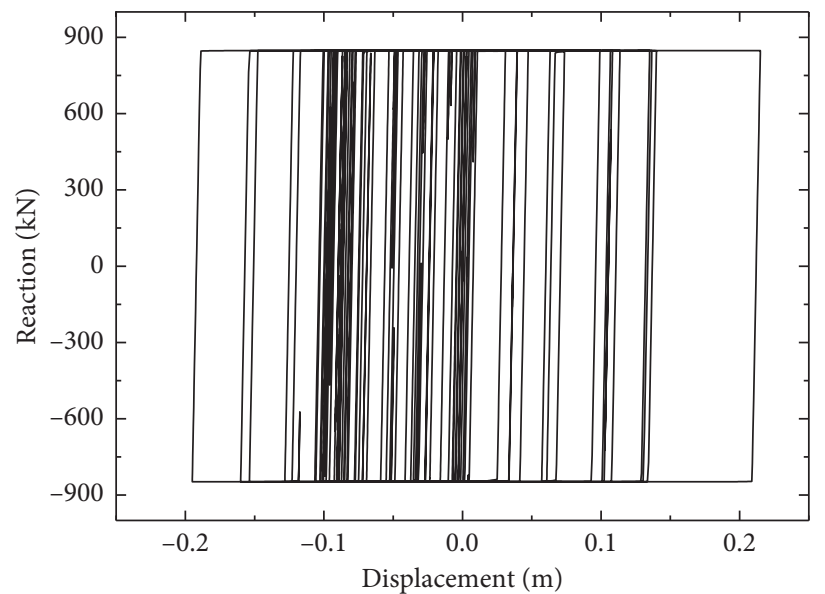

(b)

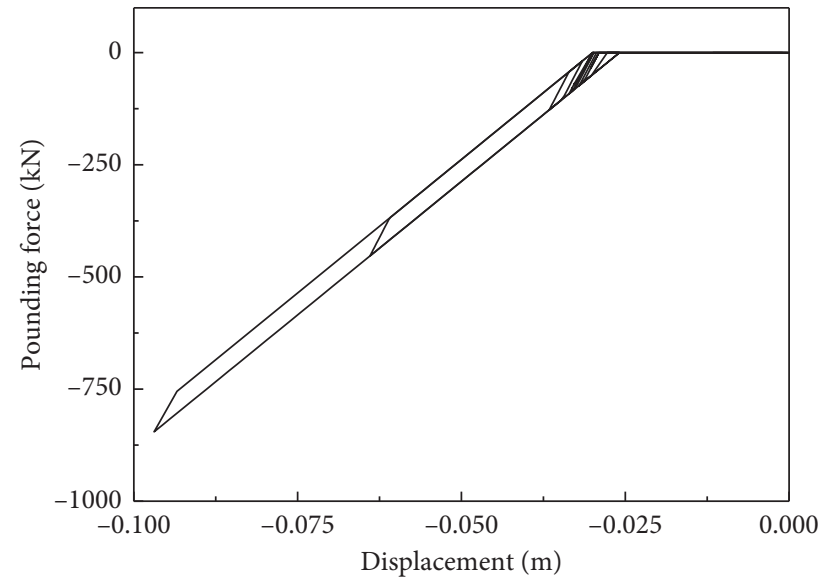

(c)

Figure 11: Force-displacement responses of various nonlinear elements of continuous beam-arch bridge under Landers earthquake motions: (a) shear key of abutment; (b) bearing; (c) pounding.

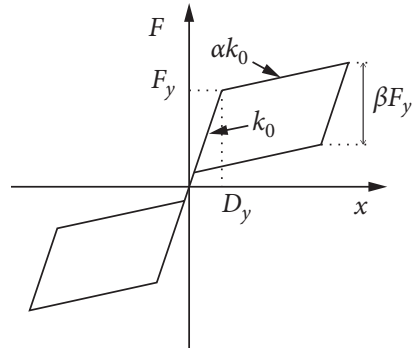

(a)

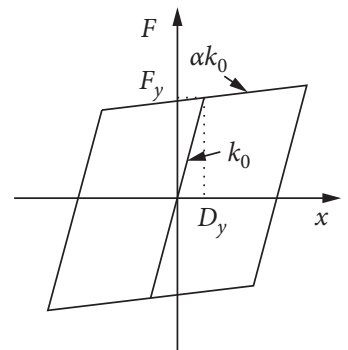

(b)

FIGURE 12: Restoring force curve: (a) SCED; (b) BRB.

TABLE 6: The mechanical parameters of the brace.

\begin{tabular}{lcccc}
\hline Type & $k_{0}(\mathrm{kN} / \mathrm{m})$ & $\alpha k_{0}(\mathrm{kN} / \mathrm{m})$ & $F_{y}(\mathrm{kN})$ & $D_{y}(\mathrm{~mm})$ \\
\hline BRB & 1000000 & 32900 & 2350 & 2.35 \\
SCED & 1000000 & 32900 & 2350 & 2.35 \\
\hline
\end{tabular}


TABLe 7: The relative displacement and residual displacement between pier and girder under different analysis cases (mm).

\begin{tabular}{lccccc}
\hline \multirow{2}{*}{ Position } & \multicolumn{3}{c}{ Relative displacement } & \multicolumn{3}{c}{ Residual displacement } \\
& Case 1 & Case 2 & Case 3 & Case 1 & Case 2 \\
\hline Abutment & 120 & 19 & 38 & 29.01 & 3.74 \\
Pier & 106 & 42 & 54 & 28.61 & 0.027 \\
\hline
\end{tabular}

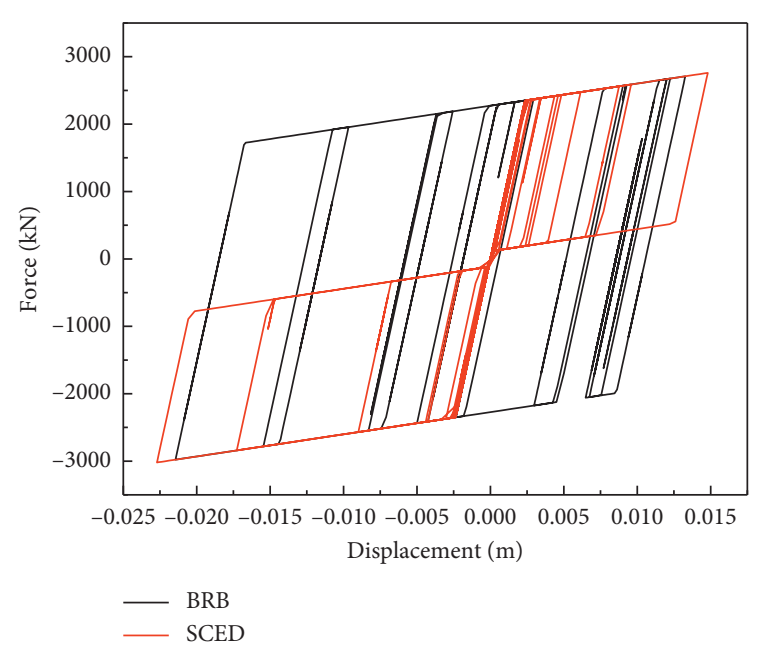

(a)

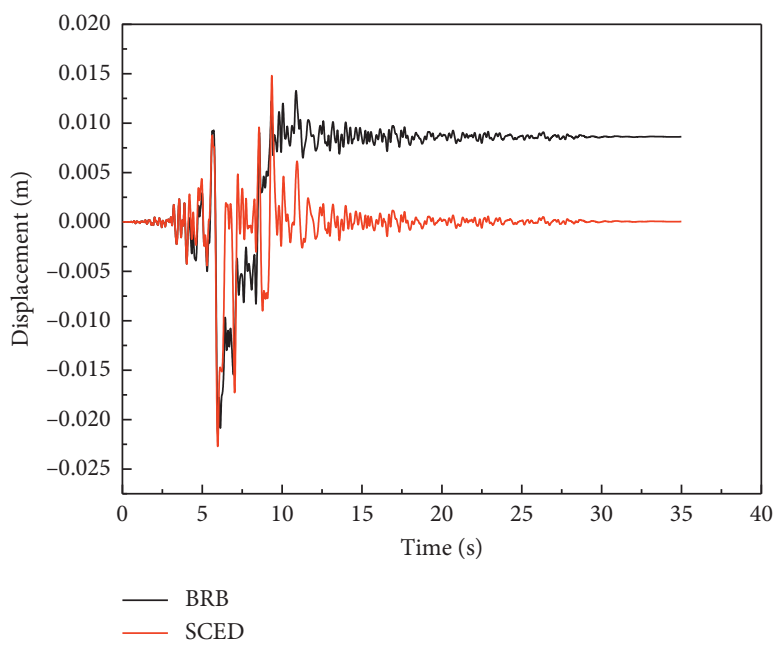

(b)

FIGURE 13: Hysteretic curve and displacement time-history curves of braces: (a) hysteresis curve; (b) displacement time-history curves.

bearings. The ground motion record was input along the lateral direction of the bridge to perform the time-history analysis.

5.2.1. Seismic Response at the Critical Locations. Table 7 shows the relative displacement and residual displacements between the pier and girder for the different analysis cases. It can be seen that, under the earthquake excitations, the relative displacement and residual displacement between the pier and girder of the isolated bridge were much smaller than those of the non-isolated bridge. Further, the SCED and BRB braces' displacement satisfied the design requirements. Both SCED and BRB braces can control the relative displacement between piers and beams under earthquake actions. Figure 13(a) shows the hysteresis curves of SCED and BRB at the pier under the action of the Imperial Valley earthquake. It can be seen that the areas enveloped by the black curve is larger than the areas enveloped by the red one, which indicates that the BRB has stronger energy dissipation capacity than SCED. As a result, the BRB performs better compared to SCED in reducing the displacement demand.

Two types of brace, BRB and SCED, are able to reduce the residual displacement significantly. As shown in Table 7, the maximum residual displacement of the bridge with no braces reaches $28.61 \mathrm{~mm}$. However, the maximum residual displacement is suppressed to 4.82 and $0.063 \mathrm{~mm}$ when the $\mathrm{BRB}$ and SCED retrofit, respectively. It also can be found that the SCED is more effective than $\mathrm{BRB}$ regarding residual displacement.

Figure 13(b) shows the sample hysteresis curves of SCED and BRB braces at the pier under the action of the Imperial Valley earthquake. It can be seen that the seismic isolation bridge with BRB brace demonstrates a larger residual displacement between the pier and girder. The residual displacement between the pier and girder of the seismic isolation bridge with the SCED brace tended to zero after the earthquake, showing an advantageous self-centering performance. For the railway bridge studied in this paper, the solid gravity piers, which have small deformation capacity and great strength, were adopted as the substructure. Therefore, the piers are required to be elastic in the seismic isolation design, so the bridge's horizontal deformation will be concentrated on the bearings. The recoverability of the bridge structure's post-earthquake function primarily is reflected in the performance state of the seismic isolation system.

5.2.2. Displacement Response of the Girder and Arch Rib. Figure 14 shows the girder and arch ribs' lateral displacement under different cases. It can be seen that the girder's transverse displacement of the seismic isolation bridge based on function separation was smaller than that of the nonisolation bridge. The girder's transverse displacement of the seismic isolation bridge in side-span and pier was the minimum, and the transverse displacement was the largest in the mid-span. The transverse displacements of the 


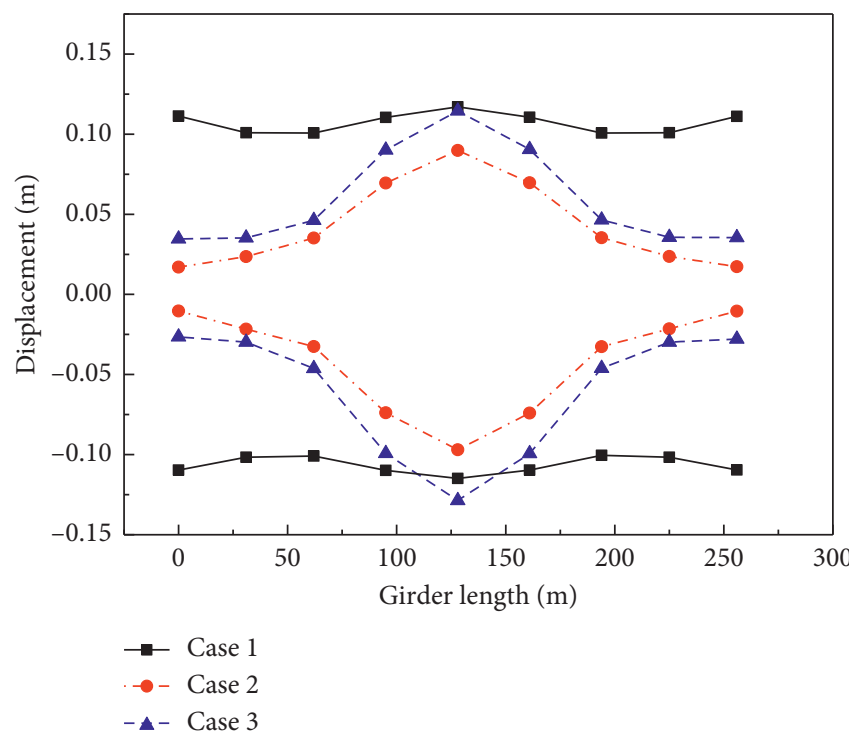

(a)

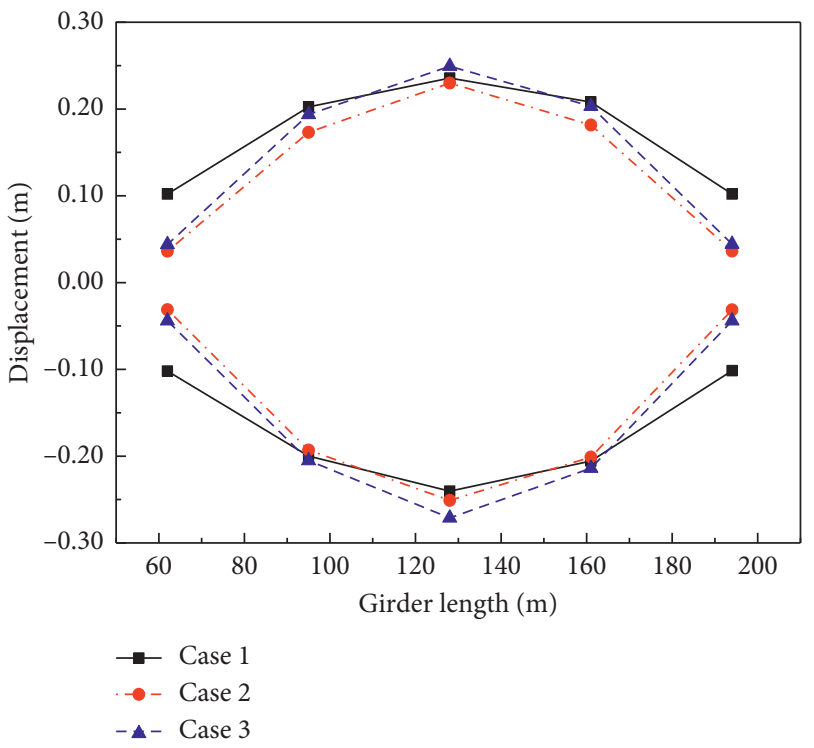

(b)

Figure 14: The lateral displacement of the girder and arch rib of a continuous beam-arch bridge: (a) girder; (b) arch rib.

TABLE 8: Combined design scheme of SCED and BRB.

\begin{tabular}{lccc}
\hline Case 4 & SCED $(n)$ & BRB & Self-centering force ratio $\zeta$ \\
\hline 1 & 10 & 2 & 0.124 \\
2 & 8 & 4 & 0.099 \\
3 & 6 & 6 & 0.074 \\
4 & 4 & 8 & 0.050 \\
5 & 2 & 10 & 0.025 \\
\hline
\end{tabular}

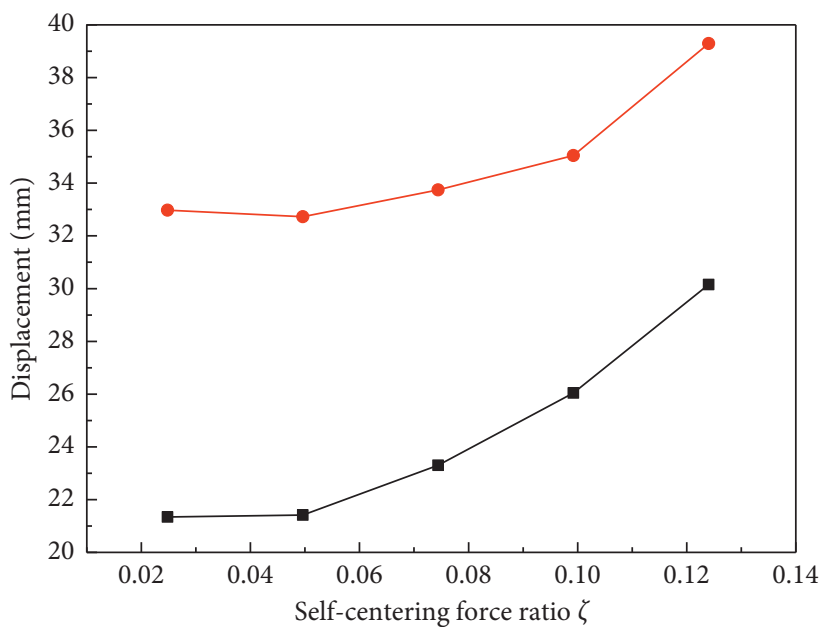

- Abutment

$\rightarrow$ Pier

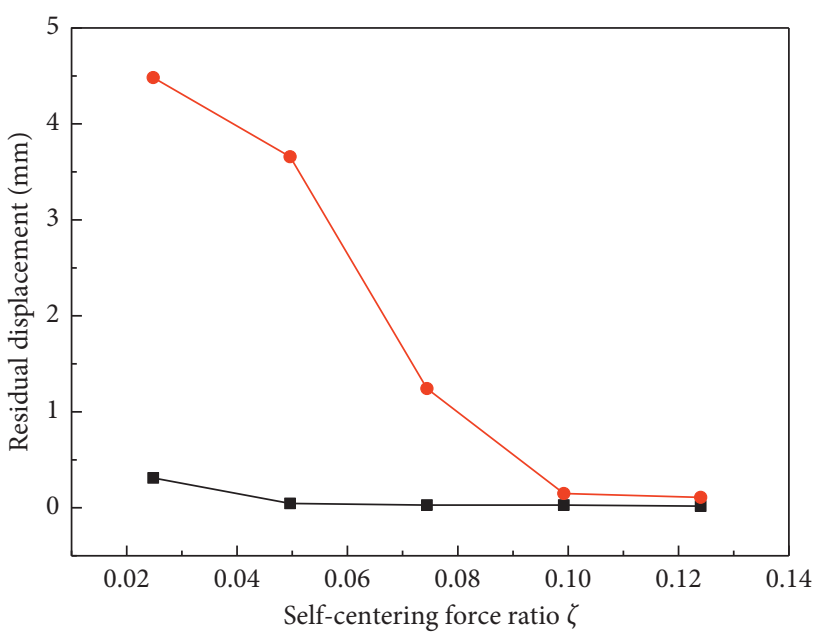

$\rightarrow$ Abutment

$\rightarrow$ Pier

(a)

(b)

FiguRE 15: The relationship between self-centering force ratio and displacement, residual displacement of braces: (a) displacement; (b) residual displacement. 


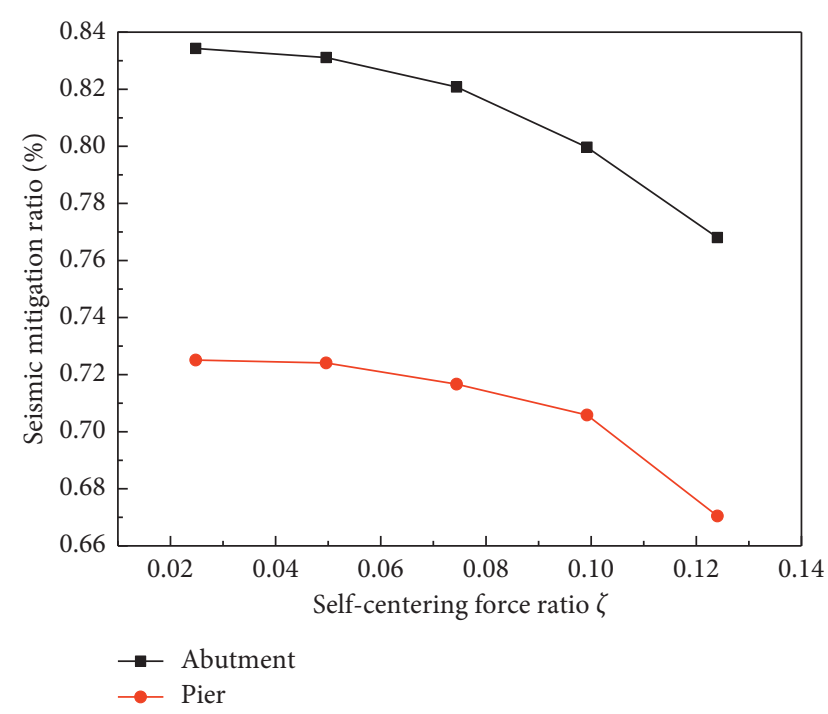

FIGURE 16: The relationship between seismic mitigation ratio and self-centering force ratio.

non-isolated bridge's girder tended to be substantially the same, all of which were approximately $11 \mathrm{~cm}$. With respect to the arch ribs' transverse displacement, the BRB and SCED braces reduced the arch foot's lateral displacement and increased the arch crown's displacement. It can be seen that the BRB and SCED have the effect of controlling the girder and arch ribs' transverse displacement, and, furthermore, this effect is more distinct for the girder.

\subsection{Seismic Response of SCED and BRB Combined Isolation} Bridges. In Cases 2 and 3, it can be seen that SCED or BRB can dissipate a portion of the input seismic energy and control the relative displacement between girders and piers under earthquake excitation. However, the displacement control effect of BRB is stronger than that of SCED, and the residual displacement of SCED tends to zero after earthquake. Therefore, the seismic isolation system combining SCED and BRB was proposed. Based on the principle of equal stiffness design, five kinds of SCED and BRB combined seismic isolation design schemes were proposed, as shown in Table 8 .

In order to determine the optimal combination design scheme, the non-dimensional parameter self-centering force ratio $\zeta$ is defined. The self-centering force ratio is calculated using the following equation:

$$
\zeta=\frac{n \beta F_{y s}}{W}
$$

where $F_{y s}$ is the yield force of SCED braces; $n$ is the number of SCED braces; $W$ is the weight of the bridge superstructure. Five kinds of composite seismic isolation design scheme and the corresponding values of self-centering force ratio $\zeta$ are shown in Table 8 . The nonlinear seismic response of five kinds of composite seismic isolation bridge was analyzed under earthquake excitations.

Figure 15 shows the relationship between self-centering force ratio and the maximum displacement, residual displacement of braces at the abutment and pier. It can be observed that the displacement of braces increases with the increase of the self-centering force ratio under earthquake excitations, and residual displacement decreases with the increase of the self-centering force ratio. It is shown that the displacement control effect of BRB is more obvious than that of SCED, but SCED has better self-recovery after earthquake.

Figure 16 shows the relationship between seismic mitigation ratio and self-centering force ratio. The seismic mitigation ratio is calculated by the displacement of the girder [47]. It can be found that the seismic mitigation ratio decreases with the increase of the self-centering force ratio. The combined seismic isolation system of SCED and BRB can achieve good effect of seismic isolation and the seismic mitigation ratio can exceed $66 \%$. As Figures 15 and 16 show, when the self-centering force ratio $\zeta$ is 0.074 , the residual displacement tends to zero. From the perspective of functional recoverability, it is the best combination of SCED and $\mathrm{BRB}$ seismic isolation design, and the corresponding seismic mitigation ratio is $71.6 \%$. The energy dissipation of BRB brace and the self-centering characteristics of SCED brace are utilized fully.

\section{Conclusions}

A railway continuous beam-arch bridge was regarded as the proto structure, and the influences of arch ribs on the lateral seismic response and displacement patterns were discussed. A seismic isolation system for railway bridge was proposed; a combination of bearings and braces was used in this system to achieve the functional separation. The seismic response of the continuous beam-arch bridge with different isolation schemes was studied:

(1) Compared with the continuous beam bridge of equal mass, the lateral displacement response of the beam is amplified due to the existence of arch ribs. Compared with the continuous beam-arch bridge without the constraint of the shear keys, the transverse displacement of the girder was reduced significantly if the constraint of shear keys is taken into account. The shear keys limited the transverse displacement of the girder. The arch rib's influence on the girder's displacement also was reduced because of the presence of the lateral shear keys.

(2) When the constraint of shear keys is not considered, the girder and arch rib move in the same phase. The girder and arch ribs exhibited rigid body translation or rotation along the bridge's transverse direction. When the constraint of shear keys is considered, the girders' displacement pattern exhibited rigid body translation or rotation along the transverse direction of the bridge. The arch ribs exhibited a great flexural deformation along the transverse direction of bridge.

(3) Based on the seismic isolation design concept of functional separation, the seismic isolation system with sliding bearings and energy dissipation braces (SCED, BRB) was proposed, which can significantly reduce the displacement demand of fixed pier and 
keep the pier in elastic state. In contrast, the displacement control effect of BRB is stronger than that of SCED, and the residual displacement of SCED tends to zero after earthquake.

(4) The combined use of SCED and BRB can give full play to the energy consumption of BRB and the selfcentering characteristic of SCED to achieve the seismic isolation effect; when the self-centering force ratio $\zeta$ is 0.074 , the combined seismic isolation control system can achieve the best seismic isolation effect, and the corresponding seismic mitigation ratio rate is $71.6 \%$.

\section{Conflicts of Interest}

The authors declare that they have no conflicts of interest.

\section{Acknowledgments}

This work was funded by the National Natural Science Foundation of China (Grant nos. 51768042 and 51908265) and Fund for Excellent Young Scholars of LUT (Grant no. 04-061810). The authors are grateful for their support.

\section{References}

[1] F. Xu, Z. Zhang, D. Wang, and H. Wang, "Application of a perfobond rib shear connector group in a beam-arch hybrid bridge," Structural Engineering International, vol. 25, no. 4, pp. 414-418, 2015.

[2] D. H. Yan, X. F. Liu, Z. C. Tian, and G. L. Yan, “A summarized account of development and application of hybrid system arch bridges," World Bridges, vol. 2, pp. 65-67, 2007.

[3] A. P. Pagnoncelli and L. F. F. Miguel, "Methodology to obtain dynamic response of road bridges considering bridge-vehicle interactions," Practice Periodical on Structural Design and Construction, vol. 24, no. 3, Article ID 04019010, 2019.

[4] F. X. Li, J. G. Nie, and J. S. Fan, "Seismic analysis of multi-span continuous reinforced concrete rigid-frame arch-bridge," Engineering Mechanics, vol. 27, no. 12, pp. 179-185, 2010.

[5] Y. Tao, T. J. Stratford, and J. F. Chen, "Behaviour of a masonry arch bridge repaired using fibre-reinforced polymer composites," Engineering Structures, vol. 33, no. 5, pp. 1594-1606, 2011.

[6] H. Y. Gou, H. Long, Y. Bao, G. Chen, Q. H. Pu, and R. Kang, "Stress distributions in girder-arch-pier connections of longspan continuous rigid frame arch railway bridges," Journal of Bridge Engineering, vol. 23, no. 7, Article ID 04018039, 2018.

[7] H. Wang, C. Xie, D. Liu, and S. Qin, "Continuous reinforced concrete rigid-frame bridges in China," Practice Periodical on Structural Design and Construction, vol. 24, no. 2, Article ID 05019002, 2019.

[8] Y. Xie, H. Yang, Z. Zuo, T. L. Sirotiak, and M. Yang, "Optimal steel section length of the composite rigid-frame bridge," Practice Periodical on Structural Design and Construction, vol. 23, no. 3, Article ID 05018001, 2018.

[9] A. Pipinato and C. Modena, "Structural analysis and fatigue reliability assessment of the Paderno bridge," Practice Periodical on Structural Design and Construction, vol. 15, no. 2, pp. 109-124, 2010.

[10] G. L. Dai and Y. Wang, "Seismic response and cushioning research of long-span railway continuous beam-arch bridge,"
Journal of Huazhong University Science and Technology (Natural Science Edition), vol. 43, no. 7, pp. 19-23, 2015.

[11] X. J. Cao, W. C. Yuan, and Y. Gao, "A seismic design of longspan continuous beam-arch combination bridges," Earthquake Resistant Engineering and Retrofitting, vol. 32, no. 3, pp. 30-35, 2010.

[12] H. Gou, W. Zhou, C. Yang, Y. Bao, and Q. Pu, "Dynamic response of a long-span concrete-filled steel tube tied arch bridge and the riding comfort of monorail trains," Applied Sciences, vol. 8, no. 4, p. 650, 2018

[13] Y. Shi, D. S. Wang, J. P. Han, Z. G. Sun, and Z. H. Zhang, "Application status of seismic isolation for bridges and its development tendency," Earthquake Engineering and Engineering Vibration, vol. 1, no. 5, pp. 118-128, 2017.

[14] J. Li and G. Chen, "Method to compute live-load distribution in bridge girders," Practice Periodical on Structural Design and Construction, vol. 16, no. 4, pp. 191-198, 2011.

[15] M. C. Kunde and R. S. Jangid, "Seismic behavior of isolated bridges: a-state-of-the-art review," Electronic Journal of Structural Engineering, vol. 3, no. 2, pp. 140-169, 2003.

[16] B. Westermo and F. Udwadia, "Periodic response of a sliding oscillator system to harmonic excitation," Earthquake Engineering \& Structural Dynamics, vol. 11, no. 1, pp. 135-146, 1983.

[17] G. Hou and S. Chen, "Bent connection options for curved and skewed SMC bridges in low-to-moderate seismic regions," Practice Periodical on Structural Design and Construction, vol. 22, no. 4, Article ID 04017011, 2017.

[18] C. Carroll and A. Juneau, "Repair of concrete bridge deck expansion joints using elastomeric concrete," Practice Periodical on Structural Design and Construction, vol. 20, no. 3, Article ID 04014038, 2015.

[19] M. Mahamid, D. Ozevin, I. Torra-Bilal et al., "Structural design and inspectability of highway bridges," Practice Periodical on Structural Design and Construction, vol. 24, no. 3, Article ID 06019002, 2019.

[20] N. Xiang, Y. Goto, M. Obata, and M. S. Alam, "Passive seismic unseating prevention strategies implemented in highway bridges: a state-of-the-art review," Engineering Structures, vol. 194, pp. 77-93, 2019.

[21] N. L. Xiang and M. S. Alam, "Comparative seismic fragility assessment of an existing isolated continuous bridge retrofitted with different energy dissipation devices," Journal of Bridge Engineering, vol. 24, no. 8, Article ID 104019070, 2019.

[22] D. P. N. Kontoni and A. A. Farghaly, "Mitigation of the seismic response of a cable-stayed bridge with soil-structureinteraction effect using tuned mass dampers," Structural Engineering \& Mechanics, vol. 69, no. 6, pp. 699-712, 2019.

[23] J. Erochko, C. Christopoulos, and R. Tremblay, "Design and testing of an enhanced-elongation telescoping self-centering energy-dissipative brace," Journal of Structural Engineering, vol. 141, no. 6, Article ID 04014163, 2015.

[24] R. Tremblay, M. Lacerte, and C. Christopoulos, "Seismic response of multistory buildings with self-centering energy dissipative steel braces," Journal of Structural Engineering, vol. 134, no. 1, pp. 108-120, 2008.

[25] A. Nikkhoo, A. B. Eskandari, A. Farazandeh, and I. Hajirasouliha, "Vibration control of bridges under simultaneous effects of earthquake and moving loads using steel pipe dampers," Journal of Vibration and Control, vol. 25, no. 19-20, pp. 2580-2594, 2019.

[26] H. Dong, X. Du, Q. Han, H. Hao, K. Bi, and X. Wang, "Performance of an innovative self-centering buckling 
restrained brace for mitigating seismic responses of bridge structures with double-column piers," Engineering Structures, vol. 148, pp. 47-62, 2017.

[27] N. Xiang and M. S. Alam, "Displacement-based seismic design of bridge bents retrofitted with various bracing devices and their seismic fragility assessment under near-fault and farfield ground motions," Soil Dynamics and Earthquake Engineering, vol. 119, pp. 75-90, 2019.

[28] S. Elias and V. Matsagar, "Effectiveness of tuned mass dampers in seismic response control of isolated bridges including soil-structure interaction," Latin American Journal of Solids and Structures, vol. 14, no. 13, pp. 2324-2341, 2017.

[29] S. Elias, V. Matsagar, and T. K. Datta, "Effectiveness of distributed tuned mass dampers for multi-mode control of chimney under earthquakes," Engineering Structures, vol. 124, pp. 1-16, 2016.

[30] A. Matin, S. Elias, and V. Matsagar, "Distributed multiple tuned mass dampers for seismic response control in bridges," Proceedings of the Institution of Civil Engineers-Structures, vol. 173 , no. 3, pp. 217-234, 2020.

[31] P. Castaldo, D. Gino, G. Bertagnoli, and G. Mancini, "Resistance model uncertainty in non-linear finite element analyses of cyclically loaded reinforced concrete systems," Engineering Structures, vol. 211, Article ID 110496, 2020.

[32] Y. Xu, Z. Zeng, Z. Wang, and H. Yan, "Seismic study of a widened and reconstructed long-span continuous steel truss bridge," Structure and Infrastructure Engineering, vol. 1, pp. 1-11, 2020.

[33] P. Castaldo, M. Ripani, and R. L. Priore, "Influence of soil conditions on the optimal sliding friction coefficient for isolated bridges," Soil Dynamics and Earthquake Engineering, vol. 111, pp. 131-148, 2018.

[34] C. Yang, P. Okumus, and R. Ren, "A hysteretic model for selfcentering precast concrete piers with varying shear-slip between segments," Engineering Structures, vol. 188, pp. 350361, 2019.

[35] Q. Han, Z. Jia, K. Xu, Y. Zhou, and X. Du, "Hysteretic behavior investigation of self-centering double-column rocking piers for seismic resilience," Engineering Structures, vol. 188, pp. 218-232, 2019.

[36] W. Lee, H. Jeong, S. Billington, S. A. Mahin, and J. Sakai, "Post-tensioned structural concrete bridge piers with selfcentering characteristics," in Proceedings of the 2007 Structures Congress, pp. 1-15, ASCE, Reston, VA, USA, 2007.

[37] M. A. ElGawady and A. Sha'lan, "Seismic behavior of selfcentering precast segmental bridge bents," Journal of Bridge Engineering, vol. 16, no. 3, pp. 328-339, 2011.

[38] W. W. Yang, "A brief overview of C270 viaduct design of Taiwan HSR project," Journal of the China Railway Society, vol. 29, no. 3, pp. 132-136, 2007.

[39] Ministry of Railways of the People's Republic of China (MRPRC), Code for Seismic Design of Railway Engineering, GB50111-2006, Ministry of Railways of the People's Republic of China (MRPRC), Beijing, China, 2006.

[40] Ministry of Transport of the People's Republic of China (MTPRC), Guidelines for Seismic Design of Highway, JTG/T B02-01-2008, Ministry of Transport of the People's Republic of China (MTPRC), Beijing, China, 2008.

[41] Ministry of Transport of the People's Republic of China (MTPRC), Series of Elastomeric Pad Bearings for Highway Bridges, JT/T 663-2006, Ministry of Transport of the People's Republic of China (MTPRC), Beijing, China, 2006.

[42] S. H. Megally, P. F. Silva, and F. Seible, "Seismic response of sacrificial shear keys in bridge abutments," Systems research report SSRP-2001/23, Department of Structural Engineering, University of California, San Diego, CA, USA, 2001.

[43] P. F. Silva, S. Megally, and F. Seible, "Seismic performance of sacrificial exterior shear keys in bridge abutments," Earthquake Spectra, vol. 25, no. 3, pp. 643-664, 2009.

[44] D. S. Wang, H. N. Li, G. X. Wang, and M. G. Yue, "Study on characters of long period portion of inelastic spectra," Earthquake Engineering and Engineering Vibration, vol. 26, no. 2, pp. 49-55, 2006.

[45] H. Dwairi and M. Kowalsky, "Implementation of inelastic displacement patterns in direct displacement-based design of continuous bridge structures," Earthquake Spectra, vol. 22, no. 3, pp. 631-662, 2006.

[46] C. Christopoulos, R. Tremblay, H.-J. Kim, and M. Lacerte, "Self-centering energy dissipative bracing system for the seismic resistance of structures: development and validation," Journal of Structural Engineering, vol. 134, no. 1, pp. 96-107, 2008.

[47] Y. Shi, Z. H. Zhang, J. P. Han, and B. K. Chen, "Self-centering performance of long-span railway continuous beam-arch bridge subjected to near-fault ground motions," Journal of Harbin Engineering University, vol. 41, no. 3, 2020.

[48] H. Dong, X. Du, Q. Han, and K. Bi, "Numerical studies on the seismic performances of RC two-column bent bridges with self-centering energy dissipation braces," Journal of Structural Engineering, vol. 146, no. 4, 2020. 